\title{
Thrombosis of a double vena cava associated with a retroperitoneal tumor
}

\author{
Lova Hasina Ny Ony Narindra Rajaonarison ${ }^{1}$, Hasina Ursèle Andrianarimanitra ${ }^{1}$, Hery \\ Rafanomezantsoa', J ean Noel Bruneton², Ahmad Ahmad ${ }^{1}$ \\ 1. Medical Imaging Department, Joseph Ravoahangy Andrianavalona Hospital, Antananarivo, Madagascar. 2. Hôpital \\ Princesse Grace, Monaco.
}

Correspondence: Lova Hasina Ny Ony Narindra Rajaonarison. Address: Medical Imaging Department, Joseph Ravoahangy Andrianavalona Hospital, Antananarivo 101, Madagascar. E-mail: rlovahasina@gmail.com

Received: July 7, 2014

DOI : $10.5430 / j b g c . v 4 n 4 p 63$

Online Published: November 24, 2014

Accepted: August 3, 2014

\section{Abstract}

Double inferior vena cava is a rare congenital anomaly. Its association with caval thrombosis is rarely reported. The authors report the case of a 36 year old woman who presented a double inferior vena cava that one was thrombosed and associated with a wide left adrenal mass, in order to precise the role of medical imaging in the management of this pathology.

\section{Key words}

Double inferior vena cava, Caval thrombosis, Adrenal mass, Medical imaging

\section{I ntroduction}

Double inferior vena cava is a rare congenital anomaly resulting from persistent of venous system which should regress during embryonic development ${ }^{[1]}$. It is often asymptomatic and discovered incidentally during radiological exploration for some reason ${ }^{[2,3]}$. Association with thrombosis or retroperitoneal abnormality is rarely reported ${ }^{[4]}$. We report the case of a 36 year old woman who presented a thrombosed double inferior vena cava associated with a retroperitoneal tumor, in order to precise the role of medical imaging in the management of this pathology. An en bloc resection of the tumor was performed after laparotomy by anterior approach and venous recanalization by dissection and thrombectomy of the left vena cava and of the left renal vein. The left adrenal vein was sectioned. The control of hemostasis was facilitated thanks to the data on retroperitoneal vessels and tumor vasculature on CT images.

\section{Observation}

A 36 year old woman was referred to our medical imaging unit for hypercortisolism and secondary hypertension. In her obstetric history, there was a notion of threat premature birth of her last child, motivating a corticosteroid therapy during pregnancy.

Clinical examination revealed a blood pressure at 160/90 $\mathrm{mmHg}$, cushingoid facies, bruises on the upper limbs, brittle nails, abdominal stretch marks and edema of bilateral lower limbs. 
Biology showed hypercortisolemia $(28.8 \mathrm{mg} / \mathrm{dl})$ and hypercortisoluria $(737.1 \mathrm{mg} / \mathrm{dl})$. Glycaemia, cholesterolemia and coagulation tests were normal.

Abdominal ultrasonography showed: two parallel tubular structures, in left and right latero-aortic localization and whose one on the left side presented no visible vascular flow at Doppler (see Figure 1); a thrombosis of the left renal vein and a left adrenal mass of malignant appearance.

Figure 1. Abdominal ultrasonography showing two tubular structures, symmetric to the aorta and whose one on the left side presented no visible vascular flow at Doppler.

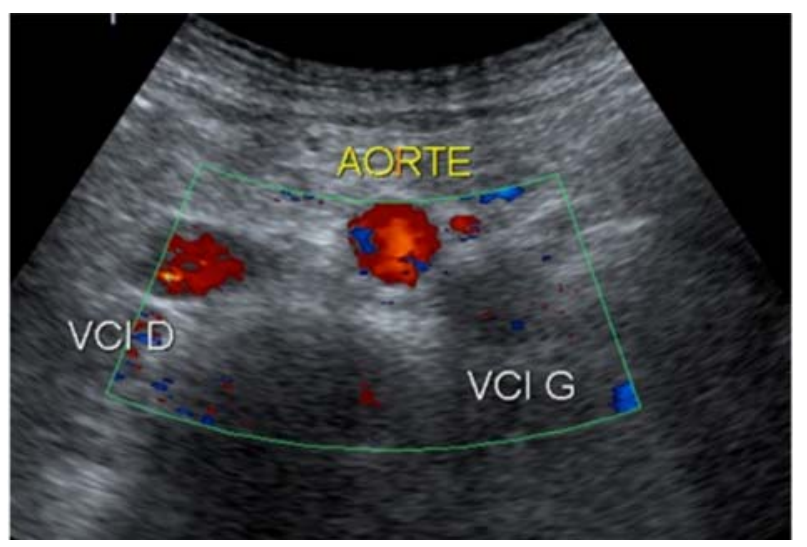

The abdominopelvic CT scan performed within the pre-therapeutic assessment found a wide left adrenal mass with malignant appearance, associated with retroperitoneal adenopathies. It also showed a double inferior vena cava with expansion and extensive thrombosis of the left vena cava (see Figure 2) associated with thrombosis of the left adrenal vein and the bilateral renal vein. The left renal vein joined the left inferior vena cava and the right renal vein in the right vena cava. Then, the left inferior vena cave joined the right inferior vena cava up to the renal veins. These thromboses were accompanied by varicose veins in left renal hilum and at para-uterine with expansion of bilateral gonadal veins that remained permeable. Thus, five large retroperitoneal vascular trunks parallel centered through the aorta were visualized (see Figure 3). On the right side, the inferior vena cava came from the confluence of the right and left common iliac veins but the left vena cava was the continuity of the left iliac vein after the origin of the common iliac (see Figure 4).

Figure 2. CT scan of the abdomen with coronal reformatted image demonstrating a left adrenal mass (arrows), retroperitoneal adenopathies (curved arrow), and double inferior vena cava (notched arrows) with extensive thrombosis of the left vena cava.

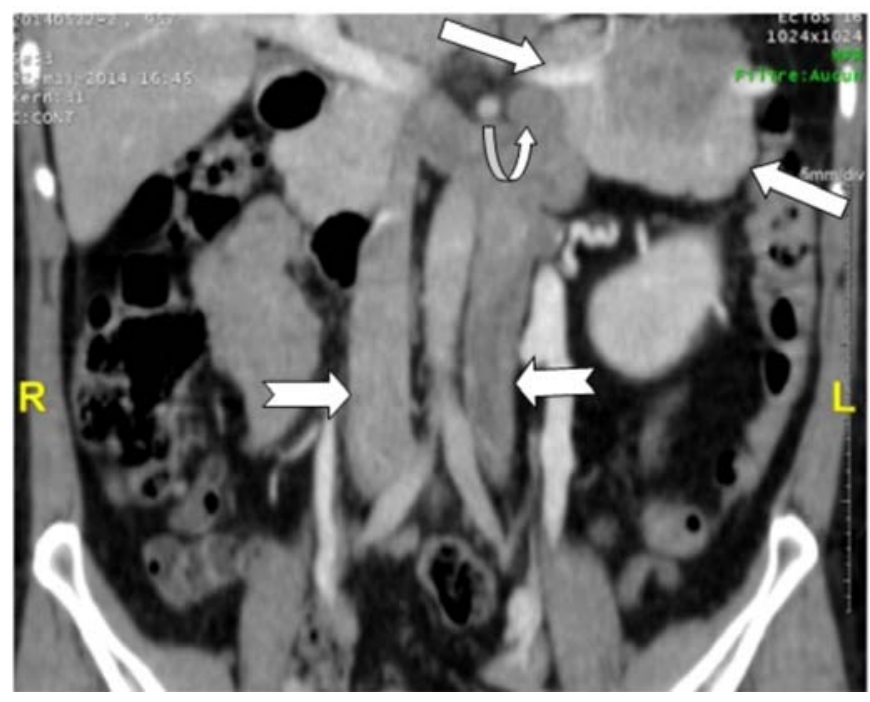

An en bloc resection of the tumor was performed after laparotomy by anterior approach and venous recanalization by dissection and thrombectomy of the left vena cava and of the left renal vein. The left adrenal vein was sectioned. The control of hemostasis was facilitated thanks to the data on retroperitoneal vessels and tumor vasculature on CT images. The postoperative course were good. 


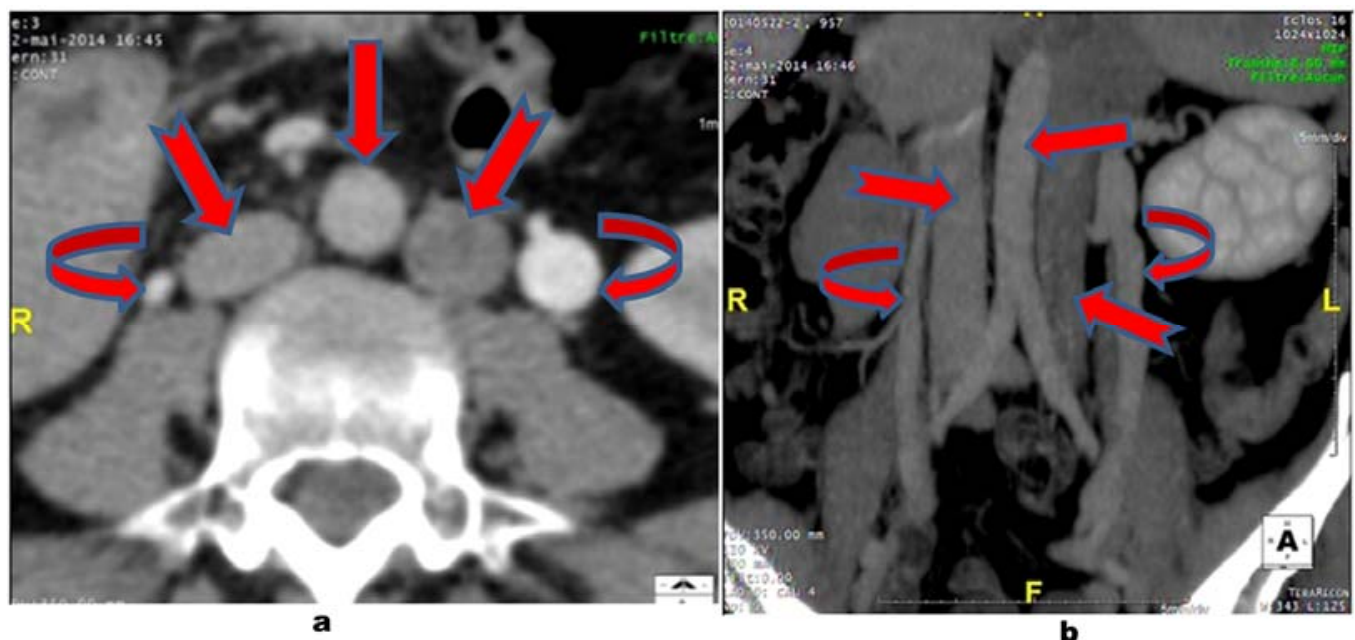

Figure 3. CT scan of the abdomen with axial (a) and coronal reconstruction (b) showing five large retroperitoneal vascular trunks centered through the aorta (arrow): right gonadal vein dilated (curved right arrow), right vena cava (notched right arrow), left vena cava (notched left arrow) and left gonadal vein dilated (curved left arrow).
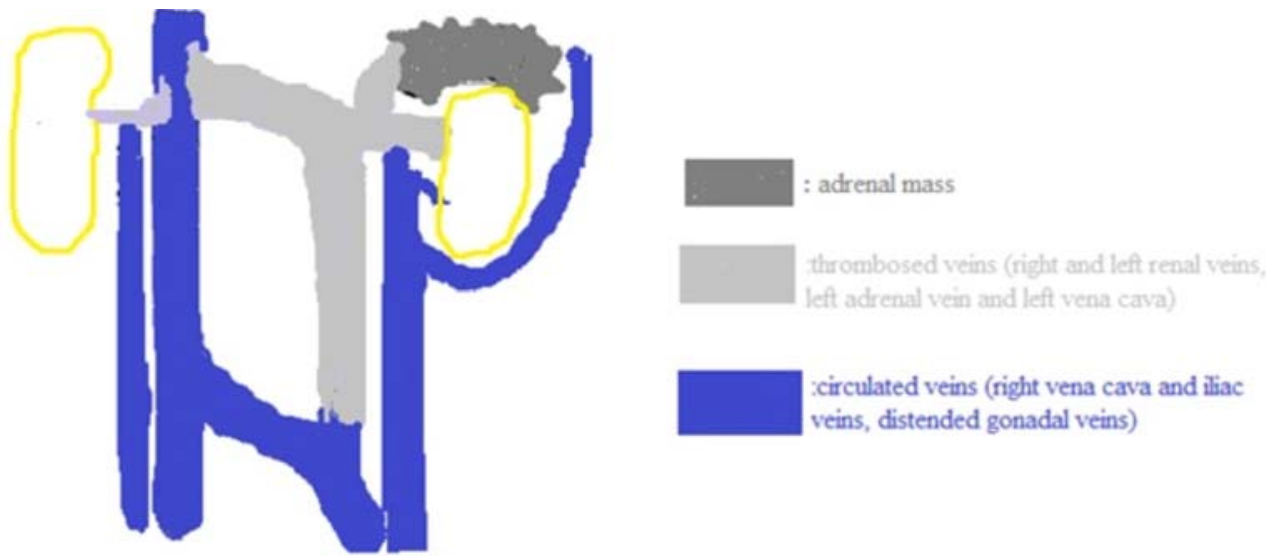

:circulated veins (right vena cava and wiac veins, distended gonadal veins)

Figure 4. Schematic reconstruction of the altered veins. The right vena cava comes from the right and left common iliac veins but the left vena cava is the continuity of the left iliac vein after the origin of the common iliac vein.

\section{Discussion}

Double inferior vena cava is a rare entity with an incidence of $0.2 \%$ to $3 \%{ }^{[5,6]}$. In most of cases, it is asymptomatic and discovered incidentally during radiological exploration for various reason ${ }^{[2]}$.

Embryogenesis of the inferior vena cava begins about the sixth week of gestation and is completed by the tenth week ${ }^{[2,3]}$. This is a complex process involving development, regression, anastomosis and replacement of different embryonic veins ${ }^{[3,7]}$. Posterior cardinal veins appear first on the posterior side of the embryo and then regress except at their caudal part where they persist and give the common iliac veins and inferior vena cava bifurcation. Right supracardinal vein, in its abdominal area becomes the inferior vena cava between the kidneys and the bifurcation, but left supracardinal vein normally regresses. Right subcardinal vein remains to form the vena cava for pre-renal and renal segment while the left subcardinal vein regresses completely. The upper part of the right vitelline vein becomes the terminal portion of the inferior vena cava between the liver and the heart ${ }^{[3,8,9]}$. Anomalies of the inferior vena cava result from the failure of the normal embryogenesis ${ }^{[3]}$ and a double inferior vena cava occurs because of the persistence of the right and left supracardinal veins ${ }^{[5,8]}$. In this reported case, it is a persistence of the left supracardinal vein with regression of the left subcardinal vein and normal development of the right supracardinal and subcardinal veins because a right and a left 
common iliac veins converged toward the right inferior vena cava and the left inferior vena cava is a direct continuation of the left external iliac vein after the origin of the common iliac vena. Thus there are two normal common iliac veins in this patient. For most of the published cases, there are four common iliac veins in the patient with double vena cava ${ }^{[2,3,5-7]}$; in each vena cava drain two common iliac veins.

Although congenital venous abnormalities have been identified as a risk factor for deep vein thrombosis ${ }^{[2,10]}$, this association remains underreported and thrombosis of a double inferior vena cava is exceptional ${ }^{[2,4]}$. According to Gayer, venous stasis due to abnormality of the vena cava would increase the likelihood of thrombosis occurring ${ }^{[11]}$. A tumoral origin by progressive extension of endoluminal venous thrombosis is possible, as in this case due to the presence of the left adrenal tumor. However, thrombosis of the left adrenal vein and the left renal vein, by the tumor, to its drainage into the left inferior vena cava can cause blood stasis with thrombosis formation in downstream.

On CT scan, double inferior vena cava appears as two tubular vascular structures, parallel to the aorta. As described in our case and by Gayer, the left inferior vena cava follows the left common iliac vein and the left renal vein drains into the left inferior vena cava ${ }^{[11]}$. Recognition of CT features of the anomaly of inferior vena cava can avoid misinterpretation ${ }^{[7]}$ and has an important clinical implication ${ }^{[3,12]}$, especially in choosing the right approach during retroperitoneal surgery as this left adrenal tumor or other invasive procedures ${ }^{[12,13]}$. Thus, a misunderstanding of the anomaly can cause wound of the collateral or ligation of either venous channels, source of serious complications; one vena cava filter may be ineffective for the prevention of recurrent pulmonary embolism ${ }^{[14]}$. Furthermore, the presence of a vena cava thrombosis may cause dilation of other venous structure in downstream as the left renal vein and the adrenal vein, the gonadal vein with development of varicose collateral circulation; which will make surgical management again delicate. Thus, thrombosis of the left inferior vena cava and the bilateral renal veins extended to their anastomosis with the right inferior vena cava was the origin of the expansion of the gonadal veins and the formation of pelvic varices in this observation, explaining the presence of five large retroperitoneal vascular trunks, from right to left: the right gonadal vein (dilated), the right inferior vena cava, aorta, the left inferior vena cava and the left gonadal vein (dilated).

Other researchers employed fractal analysis for characterizing tumors vascularization in contrast enhanced CT images ${ }^{[15]}$. This technic may predict the aggressiveness of the studied tumor thereby allowing to provide for a security margin during the resection and to predict a response to drug therapies ${ }^{[15,16]}$. Due to the treelike structure of vessels, which can be considered as fractal structures, fractal analysis could be used in the diagnosis of double-inferior vena cava and especially in case of thrombotic complications. Thus, the collateral circulation could be better explored and tumor or cruoric nature of thrombosis would be better analyzed.

\section{Conclusion}

Double inferior vena cava and its association with a vena cava thrombosis is a rare entity. It particularly interested radiologists and surgeons since its good radiological characterization allow better surgical approach of retroperitoneal lesions and taking therapeutic treatment of associated thromboembolic diseases.

\section{Conflict of interests}

The authors declare no conflict of interests of the reported manuscript.

\section{References}

[1] Ichikawa T, Kawada S, Yamashita T, Niwa T, Iino M, Koizumi J, et al. A case of right double inferior vena cava with circumcaval ureter. Jpn J Radiol. 2014. http://dx.doi.org/10.1007/s11604-014-0312-2

[2] Jones O, Oweis D, Gedela VR, Mason PF. Duplicated inferior vena cava with associated ilio-femoral deep vein thrombosis. BMJ Case Reports. 2010. http://dx.doi.org/10.1136/bcr.03.2010.2838 
[3] Ng W T, Ng S S M. Double inferior vena cava: a report of three cases. Singapore Med J. 2009; 50(6): 211-213.

[4] Tamizifar B, Seilani P, Zadeh MR. Duplication of the inferior vena cava and thrombosis: A rare case. J Res Med Sci. 2013; 18(10): 911-913. PMid: 24497866.

[5] Kellman GM, Alpern MB, Sandier MA, Craig BM. Computed tomography of vena caval anomalies with embryologic correlation. RadioGraphics. 1988; 3(8): 533-556. PMid: 3380993. http://dx.doi.org/10.1148/radiographics.8.3.3380993

[6] Masood J, Barua JM. Images in clinical medicine. Duplication of the inferior vena cava. New England Journal of Medicine. 2007; 356: e17. PMid: 17476004. http://dx.doi.org/10.1056/NEJMicm061036

[7] Nagashima T, Lee J, Andoh K, Itoh T, Tanohata K, Arai M, et al. Right Double Inferior Vena Cava: Report of 5 Cases and Literature Review. J Comput Assist Tomogr. 2006; 30: 642-645. PMid: 16845296. http://dx.doi.org/10.1097/00004728-200607000-00014

[8] Srivastaval A, Singh KJ, Suri A, Vijjan V, Dubey D. Inferior Vena Cava in Urology: Importance of Developmental Abnormalities in Clinical Practice. The Scientific World Journal. 2005; 5: 558-563. PMid: 16075153. http://dx.doi.org/10.1100/tsw.2005.66

[9] Linthoudt H, Stockx L, Verhaeghe R, Vermylen J. Are the congenital anomalies of the inferior vena cava predispose to thrombosis? Blood Thrombosis Vessels. 1996; 9(8): 551-556.

[10] María J, García-Fuster, Forner MJ, Flor-Lorente B, Soler J, Camposc S. Inferior Vena Cava Malformations and Deep Venous Thrombosis. Rev Esp Cardiol. 2006; 59(2): 171-175.

[11] Gayer G, Luboshitz J, Hertz M, Zissin R, Thaler M, Lubetsky A. Congenital Anomalies of the Inferior Vena Cava Revealed on CT in Patients with Deep Vein Thrombosis. AJR. 2003; 180: 729-732. PMid: 12591684. http://dx.doi.org/10.2214/ajr.180.3.1800729

[12] Sartori MT, Zampieri P, Andres AL, Prandoni P, Motta R, Miotto D. Double vena cava filter insertion in congenital duplicated inferior vena cava: a case report and literature review. Haematologica. 2006; 91(6): 85-86.

[13] Arudchelvam JD, Gunawardena RM, Dissanayake LR, Cassim MRN, Wijeyaratne SM. Double inferior vena cava: beware! Ceylon Medical Journal. 2013; 58: 38-39. PMid: 23549726. http://dx.doi.org/10.4038/cmj.v58i1.5366

[14] Zunon-Kipré Y, Broalet E, Kakou M, Ouattara D. Une variante anatomique rare: la duplication de la veine cave inferieure. Description et implications chirurgicales. Rev. Int Sc Méd. 2006; 8(3): 49-52.

[15] Al-Kadi OS, Watson D. Texture Analysis of Aggressive and non-Aggressive Lung Tumor CE CT Images. IEEE Transactions on Biomedical Engineering. 2008; 55: 1822-1830. PMid: 18595800. http://dx.doi.org/10.1109/TBME.2008.919735

[16] Savage VM, Herman AB, West GB, Leu K. Discrete Continuous Dyn Syst Ser B. 2013. http://dx.doi.org/10.3934/dcdsb.2013.18.1077 